University of Nebraska - Lincoln

DigitalCommons@University of Nebraska - Lincoln

8-1-2008

\title{
Diet influences mate choice selectivity in adult female wolf spiders
}

\author{
Eileen Hebets \\ University of Nebraska - Lincoln, ehebets2@unl.edu \\ Jennifer Wesson \\ University of California, Berkeley, U.S.A. \\ Paul S. Shamble \\ University of California, Berkeley, U.S.A.
}

Follow this and additional works at: https://digitalcommons.unl.edu/bioscihebets

Part of the Behavior and Ethology Commons

Hebets, Eileen; Wesson, Jennifer; and Shamble, Paul S., "Diet influences mate choice selectivity in adult female wolf spiders" (2008). Eileen Hebets Publications. 29.

https://digitalcommons.unl.edu/bioscihebets/29

This Article is brought to you for free and open access by the Papers in the Biological Sciences at DigitalCommons@University of Nebraska - Lincoln. It has been accepted for inclusion in Eileen Hebets Publications by an authorized administrator of DigitalCommons@University of Nebraska - Lincoln. 
Published in Animal Behaviour 76:2 (August 2008), pp. 355-363; doi 10.1016/j.anbehav.2007.12.021

Copyright (C) 2008 The Association for the Study of Animal Behaviour; published by Elsevier Ltd.

http://www.sciencedirect.com/science/journal/00033472 Used by permission.

Submitted October 15, 2007; revised November 12, 2007; accepted December 4, 2007; published online June 9, 2008.

\title{
Diet influences mate choice selectivity in adult female wolf spiders
}

\author{
Eileen A. Hebets, ${ }^{*}$ Jennifer Wesson, ${ }^{* *}$ and Paul S. Shamble ** \\ * School of Biological Sciences, University of Nebraska-Lincoln, Lincoln, U.S.A. \\ (Correspondence: 348 Manter Hall, School of Biological Sciences, \\ University of Nebraska-Lincoln, Lincoln, NE 68588) \\ ** Department of Integrative Biology, University of California, Berkeley, U.S.A. \\ (J. Wesson is now at 5589 E. Park Circle Dr., \#103, Fresno, CA 93727, and \\ P. S. Shamble is now at 744 Cornell Dr., Santa Clara, CA 95051)
}

\begin{abstract}
Most studies of female choice have assumed that mating preferences are shared within a population or species. However, variation both within and among females exists in natural populations, and foraging history is among the many ways in which females may vary. Here, we used diet manipulations in an effort to understand how foraging history influences female mate choice. Immature Schizocosa wolf spiders collected from a mixed population of brush-legged and non-ornamented males were reared in the laboratory on two diets that varied in both quality and quantity (low/high diet). For low- and high-diet individuals, we recorded data on rates of development, adult size and adult mate choice. Consistent with previous work, we found that high-diet spiders matured more quickly and were significantly larger as adults than low-diet spiders. Males also matured earlier than females. Body condition varied with diet treatment and sex. High-diet individuals and females were both characterized by better body condition indexes. In addition, high-diet brush-legged males had larger brushes than low-diet brush-legged males. Upon maturation, females were paired simultaneously with a low- and a high-diet male of the same form (brush-legged or non-ornamented) in a mate choice trial. While no obvious differences were observed in courtship and/or mating effort between males, female mate choice varied with the female's diet treatment. High-diet females mated more frequently with high-diet males than with low-diet males, whereas low-diet females showed no selectivity.
\end{abstract}

Keywords: condition dependence, female plasticity, life history, mate choice, Schizocosa, sexual selection, spider

The importance of female mate choice in the evolution of male secondary sexual traits is unequivocal (reviewed in Andersson, 1994), yet the extent of variation in female mate choice within and among populations remains unclear (Jennions and Petrie, 1997; Widemo and Saether, 1999). Although modern theories of sexual selection rely on consensus female mating preferences (reviewed in Andersson, 1994), recent studies have highlighted the prevalence of variability in female mate choice both among and within populations (Kodric-Brown \& Nicoletto, 1996). In addition, individual females may vary over time in their mating preferences. Factors such as female parasite load (Poulin, 1994; Lopez, 1999; Pfennig and Tinsley, 2002), female age (Moore and Moore, 2001; Coleman et al., 2004; Uetz and Norton, 2007), female experience (Collins, 1995; Kodric-Brown and
Nicoletto, 2001; Hebets, 2003; Hebets and Vink, 2007), female self-perception (Little et al., 2001; Burley and Foster, 2006; Little and Mannion, 2006), and female-male compatibility can influence female preferences and/or choice. Environmental or ecological factors such as predation risk or time of year may also affect mating decisions (Hedrick and Dill, 1993; Borg et al., 2006). The extent to which female mate choice varies in natural populations has strong implications for the strength of sexual selection and, thus, for the evolution of male secondary sexual traits.

Theory predicts that variation in both mate quality and mate choice costs will influence active mate choice (Parker, 1983). Specifically, Parker's model of mate choice suggests that a female's level of choosiness is a function of her reproductive quality and, thus, we should expect to find con- 
dition-dependent mate choice (Parker, 1983; Widemo and Saether, 1999). Several recent studies have focused on how condition, or the pool of resources available to allocate to life history traits (Rowe \& Houle, 1996), influences mating behavior. For example, in female guppies, diet influences female condition and sexual responsiveness (i.e. willingness to engage in active mate choice), but not female preference functions (Syriatowicz \& Brooks, 2004). In the black field cricket Teleogryllus commodus, females reared on highprotein diets are more sexually responsive and show stronger preference functions than those reared on low-protein diets (Hunt et al., 2005). In the stalk-eyed fly Cyrtodiopsis dalmanni, females fed on corn express stronger preferences for large-eyespan males than those fed on sucrose (Hingle et al., 2001) and female preferences in the stalk-eyed fly Diasemopsis meigenii are positively associated with female eyespan, a condition-dependent trait (Cotton et al., 2006). However, not all studies of diet manipulations have led to observable differences in mate choice (Archard et al., 2006).

Here, we explore the extent to which diet influences a series of life history traits and reproductive behavior in a predatory arthropod, Schizocosa wolf spiders. For predatory arthropods, food quality as well as availability may vary tremendously throughout an environment, both spatially and temporally. In arachnids, variation in prey quality leads to significant variation in survivorship, development, body condition and secondary sexual traits (Toft and Wise, 1999; Uetz et al., 2002), all of which may have important implications for reproductive success.

Schizocosa wolf spiders are ground-dwelling predatory arthropods found commonly throughout most of North America. The genus encompasses approximately 23 described species in North America and harbors tremendous variation both among and within species with respect to male secondary sexual traits and behaviors as well as female mate choice (Stratton, 2005). Because of their abundance and diversity, considerable research has focused on the evolution of male secondary sexual traits and female choice among various Schizocosa species (Hebets, 2003; Hebets, 2005; Stratton, 2005; Hebets et al., 2006; Hebets and Vink, 2007; Uetz and Norton, 2007; reviewed in Uetz \& Roberts, 2002). Despite the plethora of studies focusing on Schizocosa, however, there is only one study to date that has examined the influence of diet on life history and secondary sexual traits. Uetz et al. (2002) found that $S$. ocreata wolf spiders raised on different life-long feeding regimes (high- versus low-quantity food) varied significantly in mortality, development time, size, condition and brush size. While this study was the first to show condition-dependent secondary sexual traits in Schizocosa, it did not assess how feeding regime might influence female mate choice.

In the present study, we use a diet manipulation experiment to examine whether variation in female diet leads to variation in female mate choice. We use spiders from a recently discovered mixed population in Mississippi, U.S.A., where both brush-legged (similar to S. ocreata) and non-ornamented (similar to $S$. rovneri) males are found syntopi- cally. In this mixed population, both behavioral as well as mitochondrial data suggest that these spiders encompass a freely interbreeding population (Hebets \& Vink, 2007). We found that diet influenced development time, size and body condition. In addition, we found that diet influenced female mate choice: females fed a high-nutrient diet discriminated among potential mates, whereas females fed a low-nutrient diet showed no mate selectivity.

\section{Methods}

\section{Spider Collecting and Rearing}

We collected immature male and female spiders from rock and leaf litter substrates on March 19 and 21, 2005, at the University of Mississippi's greenhouse in Oxford, MS, U.S.A. Spiders at this locality occur as a mixed population of brush-legged and non-ornamented male forms, which resemble Schizocosa ocreata and S. rovneri, respectively, in morphology and behavior (Hebets \& Vink, 2007). While mitochondrial sequence data distinguishes all other Schizocosa species examined to date, it does not distinguish between brush-legged and non-ornamented males from this mixed population (Hebets \& Vink, 2007). In addition, prior research on this population revealed that the mating frequency for each male form depends on a female's prior experience, providing behavioral evidence that these forms freely interbreed and thus probably represent discrete male phenotypes of a single species (Hebets \& Vink, 2007).

Individuals were brought back to the laboratory where they were immediately weighed and assigned to a diet treatment (high- versus low-nutrient diet; see below). Upon recording their initial weights, spiders were housed individually in $6 \times 6 \times 8 \mathrm{~cm}$ AMAC Plastic Products boxes (Petaluma, CA, U.S.A.). They were kept on a 12:12 h light:dark cycle and provided with a constant source of water. All spiders were fed crickets (Acheta domesticus) once per week following the diet treatments described below. Feeder crickets arrived weekly from Bassett's Cricket Ranch, Inc. (Visalia, CA, U.S.A.) and were immediately separated into one of two plastic tubs: high-nutrient feeder crickets or low-nutrient feeder crickets (see below).

\section{High-nutrient diet}

High-nutrient feeder crickets received Fluker's HighCalcium Cricket Feed (Port Allen, LA, U.S.A.), TetraColor Tropical Fish Flakes and Fluker's Calcium Fortified Cricket Quencher ad libitum. The spiders assigned to the high-nutrient diet were fed two times their body weight once per week in high-nutrient crickets.

\section{Low-nutrient diet}

Low-nutrient feeder crickets received Fluker's Calcium Fortified Cricket Quencher. Spiders assigned to the low-nutrient diet were fed one-half of their body weight once per week in low-nutrient crickets. Our diet manipulations purposefully involved both quantity and quality differences to ensure observable differences in diet treatment. 


\section{Quantifying Development and Size}

All individuals were checked every 2-3 days for molts. Every molt was recorded through to the final maturation molt. To calculate maturation time, we used the date at which spiders were brought into the laboratory (23 March) as the starting point and counted the number of days that elapsed until maturation. We also recorded the total number of molts per individual in the laboratory.

Since individuals were weighed every week immediately prior to feeding, we used the first weight recorded after maturation as an individual's "maturation weight." Upon completion of all behavioral trials, or upon death, individuals were preserved in $70 \% \mathrm{EtOH}$ to obtain accurate body measurements. Using digital dial calipers, we took three measurements each of every preserved individual's cephalothorax width (CW) and cephalothorax length (CL). The CW measurements were taken at the widest point on the cephalothorax and the CL measurements were taken at the shortest point (i.e. directly in the centre). All measurements were taken by the same individual.

To obtain accurate leg measurements, the right foreleg of each individual was removed and mounted on a microscope slide. Upon removal, the foreleg was dehydrated three times in $95 \% \mathrm{EtOH}$ and for $10 \mathrm{~min}$ and three times in $100 \% \mathrm{EtOH}$ for $10 \mathrm{~min}$. The foreleg was then removed from the $100 \% \mathrm{EtOH}$, cleared in methyl salicylate for 1.75 min and mounted on a microscope slide with PVA mounting medium. Once the slide dried, we took a digital photograph of each leg under a Leica DM 4000B microscope with a Spot Flex digital camera (Diagnostic Instruments, Inc, Sterling Heights, MI, U.S.A.) under a 1.25× objective and $1.2 \times$ camera coupler. The stage was illuminated by two fiber optic lights from above and a stage lamp from below. All photographs were taken the same day under identical lighting conditions. Digital images were imported to a computer using the software program Image Pro-Discovery (Medi Sybernetics, Bethesda, MD, U.S.A.). Using Image Pro-Discovery, we took measurements of the tibia length $(\times 3)$ and femur length $(\times 3)$ for every possible individual. For brush-legged males, we took various other measurements as well: "dorsal brush height," the distance that the brush extended above the dorsal surface of the tibia; "ventral brush height," the distance that the brush extended below the ventral surface of the tibia; "lateral brush height," the total height of the brush (including the tibia) from the lateral view; and "brush area," a measure of the entire lateral area encompassed by the brush. For every body part for which we had multiple measurements, we averaged the three measurements to give a single score per individual.

In spiders, a multivariate axis that summarizes leg lengths and cephalothorax dimensions should provide a functionally relevant measure of overall body size. Accordingly, we performed a principal component analysis on the variance-covariance matrix of the following four variables: femur length, tibia length, cephalothorax width $(\mathrm{CW})$ and cephalothorax length (CL). The analysis was conducted separately for each sex because there are differences in al- lometry between the sexes. Similarly, a multivariate axis that summarizes various brush measurements should provide a functionally relevant measure of overall brush size. Thus, we performed a principal component analysis on the variance-covariance matrix of the following four brush measurements: $\ln$ (dorsal brush height), ventral brush height, lateral brush height and $\ln$ (brush area).

\section{Mate Choice Trials}

Mate choice trials were run in circular plastic arenas measuring $20.3 \mathrm{~cm}$ in diameter by $7.6 \mathrm{~cm}$ in height (Pioneer Plastics, Inc., Dixon, KY, U.S.A.). A piece of white filter paper lined the bottom of the arena and a single oak leaf was placed in the centre to provide a refuge under which females could hide. Females were initially placed in the arena and allowed to acclimate for 2-5 min, after which time two males, a high- and a low-diet male, were introduced simultaneously at opposite ends of the arena. At least $2 \mathrm{~h}$ before introduction, we individually marked high- and low-diet males with either a red or a green dot of paint (Deco Color Paint Pens, DecoArt, Stanford, KY, U.S.A.) on their cephalothorax to ensure that we could distinguish between them once they were released into the arena. At the start of a trial, each male was placed underneath an inverted vial and both vials were lifted simultaneously. All three individuals were allowed to interact for $45 \mathrm{~min}$. Females ranged from 14 to 49 days old at the time of mate choice trials.

As described above, we tested 60 females in a single mate choice trial in which they were paired with two males simultaneously, a high-diet and a low-diet male (low-diet females: $N=32$; high-diet females: $N=28$ ). Since females were collected from a mixed population of brush-legged and non-ornamented males (see Hebets \& Vink, 2007), and females were indistinguishable, each female was randomly assigned either a brush-legged or non-ornamented male form. Of the 32 low-diet females, 16 were paired with brush-legged males and 16 were paired with non-ornamented males. Of the 28 high-diet females, 14 were paired with brush-legged males and 14 were paired with non-ornamented males.

We used 78 males in the 60 mate choice trials (2 males per trial $=120$ male slots): 38 low-diet males (brush-legged: $N=16$; non-ornamented: $N=22$ ) and 40 high-diet males (brush-legged: $N=21$; non-ornamented: $N=19$ ). Because of the limited number of individuals available, some males in each treatment were reused multiple times. Of the lowdiet males, 20 were used once, 15 were used twice, two were used three times and only one was used four times (11 brush-legged males and 7 non-ornamented males were used multiply). Of the high-diet males, 24 were used once, 13 were used twice, two were used three times and only one was used four times ( 8 brush-legged males and 8 nonornamented males were used multiply). Only one of the reused males (a high-diet male) had previously copulated and that male copulated in two of three trials. Although some males were used multiple times in a haphazard fashion, none of the low- versus high-diet male pairings were repeated and thus each male-male pairing was unique. 


\section{Results}

\section{Diet and Development}

Of the 177 field-collected immature individuals that were reared on high- and low-nutrient diets (ultimately representing 87 females and 90 males), we obtained initial weights for 175 individuals. Initial weight did not differ between individuals placed on low- and high-diet treatments (low diet: $N=84$, mean $\pm \mathrm{SE}=0.02 \pm 0.0006 \mathrm{~g}$; high diet: $N=91$, mean $\pm \mathrm{SE}=0.019 \pm 0.0006 \mathrm{~g} ; \quad F_{1,173}=1.87$, $P=0.17$, but immature individuals that ultimately became males initially weighed significantly more than immatures that ultimately became females (males: $N=90, \mathrm{~m}$ ean $\pm \mathrm{SE}=0.02 \pm 0.0006 \mathrm{~g}$; females: $N=85$, mean $\pm \mathrm{SE}=0$. $\left.018 \pm 0.0006 \mathrm{~g} ; F_{1,173}=7.22, P=0.008\right)$. The following analyses incorporate data from all 177 individuals. Male form at maturity did not depend on diet treatment (low diet: $42 \%$ developed into brush-legged males $(N=18)$ and $58 \%$ developed into nonornamented males $(N=25)$; high diet: $53 \%$ developed into brush-legged males $(N=25)$ and $47 \%$ developed into nonornamented males $(N=22)$; chi-square test: $\left.X_{1}^{2}=1.16, P=0.28\right)$. Time to maturation varied with both diet and sex. High-diet individuals matured earlier than low-diet individuals and males matured earlier than females, but we found no interaction between diet and sex (ANOVA: whole model: $F_{3,173}=11.04, P<0.0001$; effect tests: diet: $F_{1,175}=9.49, P=0.0024$; sex: $F_{1,175}=23.59$, $P<0.0001$; diet $\times$ sex: $F_{1,175}=0.66, P=0.42$; Figure 1$)$. The number of molts per individual in the laboratory prior to maturation did not depend on diet or sex (whole model: $F_{3,173}=0.17, P=0.91$; effect tests: diet: $F_{1,175}=0.08, P=0.78$; sex: $F_{1,175}=0.02, P=0.89$; diet $\left.\times \operatorname{sex}: F_{1,175}=0.41, P=0.52\right)$.

\section{Diet and Size}

Some individuals died prematurely (e.g. from parasitoids accrued in the field) or in such a way that made it impossible to get accurate body measurements (e.g. from mould or cannibalism), and thus the following analyses incorporate only the 136 individuals for which we had complete body measurements: $N=54$ females (30 low-diet and 24 highdiet) and $N=82$ males (38 low-diet, 16 brush-legged, 22 non-ornamented; 44 high-diet, 23 brush-legged, 21 non-ornamented). In cases where data were not normally distributed, we conducted transformations to normalize the data. A two-way ANOVA using a natural log transformation of the weight data revealed that maturation weight depended on diet and sex, and there was a significant interaction between the two (whole model: $F_{3,132}=26.94, P<0.0001$; effect tests: diet: $F_{1,134}=34.42, P<0.0001$; sex: $F_{1,134}=53.51$, $P<0.0001$; diet $\times$ sex: $F_{1,134}=3.9, P=0.05$; Table 1$)$. A post hoc Tukey HSD test comparing all means (JMP 6.0, SAS Institute Cary, NC, U.S.A.) revealed that high-diet females weighed more at maturation than all other groups, lowdiet males weighed less than all other groups and low-diet females and high-diet males did not differ in mean weight at maturity (Table 1).

In both sexes, the first axis of the principal component analysis (PC1) was interpretable as an overall size vector.

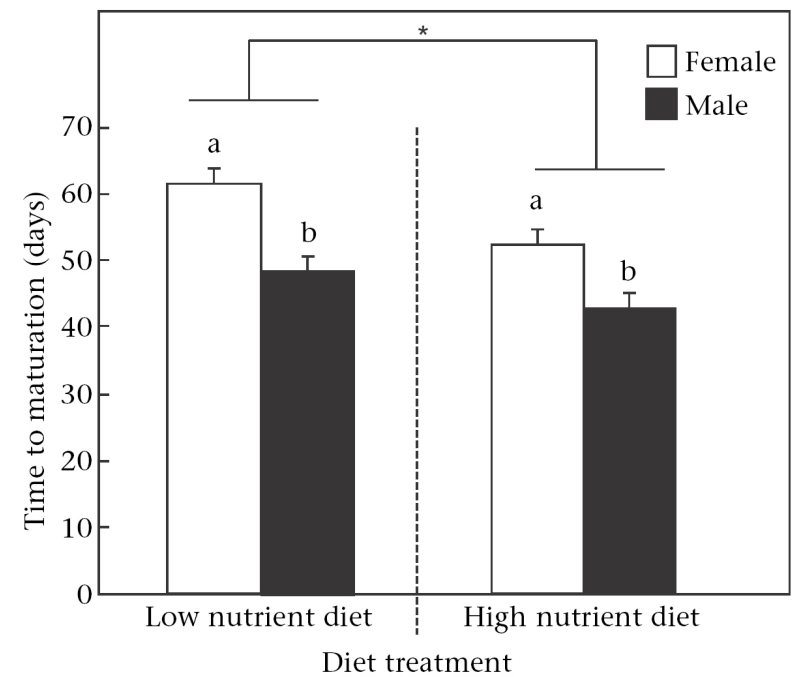

Figure 1. Development time of male and female wolf spiders reared on low- versus high-diet treatments. Time to maturation (days) was calculated from the time that individuals were brought into the laboratory (23 March) until the time they molted to maturity. Different letters indicate a significant difference $(P<0.05)$. ${ }^{*} P<0.05$.

PC1 explained 90\% of the variance among females (eigenvalue $=0.21$, and factor loadings were uniformly positive for each of the four characters: femur length $=0.45$, tibia length $=0.35, \mathrm{CW}=0.48$ and $\mathrm{CL}=0.67$. $\mathrm{PC} 1$ explained $84 \%$ of the variance among males (eigenvalue $=0.17$ ), and factor loadings were also uniformly positive for each of the four characters: femur length $=0.52$, tibia length $=0.44$, $\mathrm{CW}=0.47$ and $\mathrm{CL}=0.57$. Since our PCA analysis yielded different PC1s for males and females, we analyzed each sex separately in a one-way ANOVA looking at the effect of diet on body size. For both sexes, body size at maturity depended on diet, with low-diet individuals being smaller (females: $F_{1,52}=11.65, P=0.001$; males: $F_{1,80}=12.2$, $P=0.0008)$. As an indicator of body condition, we used residuals from a maturation weight by cephalothorax width (CW) regression in a two-way ANOVA. We found that body condition depended on diet and sex and that there was a diet by sex interaction (whole model: $F_{3,132}=11.0$, $P<0.0001$; effect tests: diet: $F_{1,134}=15.67, P=0.0001$; sex: $F_{1,134}=8.68, P=0.004$; diet $\times$ sex: $F_{1,134}=16.58, P<0.0001$; Figure 2). Using a post hoc Tukey HSD test (JMP 6.0), we found that high-diet females were in significantly better body condition than all other categories $(Q=2.6, \mathrm{a}=0.05$; Figure 2).

\section{Diet and Secondary Sexual Traits}

Complete body and brush measurements were recorded for 39 brush-legged males. The first axis of the principal component analysis (PC1) was interpretable as an overall brush size vector. PC1 explained $88 \%$ of the variance among individuals (eigenvalue $=0.05$ ), and factor loadings were uniformly positive for each of the four characters: $\ln$ (dorsal brush) height $=0.57$, ventral brush height $=0.21$, 
Table 1. Average body measurements for individuals across sex and diet treatments

\begin{tabular}{|c|c|c|c|c|c|}
\hline & $\begin{array}{c}\text { Maturation } \\
\text { weight }(\mathrm{g})\end{array}$ & $\begin{array}{l}\text { Leg } 1 \text { tibia } \\
\text { length }(\mathrm{mm})\end{array}$ & $\begin{array}{l}\text { Leg } 1 \text { femur } \\
\text { length (mm) }\end{array}$ & $\begin{array}{l}\text { Cephalothorax } \\
\text { width }(\mathrm{CW})(\mathrm{mm})\end{array}$ & $\begin{array}{c}\text { Cephalothorax } \\
\text { length }(\mathrm{CL})(\mathrm{mm})\end{array}$ \\
\hline Low diet female & $0.045 \pm 0.002_{B}$ & $2.23 \pm 0.04$ & $2.72 \pm 0.04$ & $2.76 \pm 0.04$ & $3.70 \pm 0.05$ \\
\hline High diet female & $0.067 \pm 0.003_{\mathrm{A}}$ & $2.27 \pm 0.04$ & $2.81 \pm 0.04$ & $2.92 \pm 0.04$ & $3.85 \pm 0.05$ \\
\hline High diet male & $0.042 \pm 0.002_{B}^{A}$ & $2.59 \pm 0.03$ & $2.97 \pm 0.03$ & $2.67 \pm 0.03$ & $3.46 \pm 0.04$ \\
\hline
\end{tabular}

Different subscript letters indicate significant differences $(P<0.05)$.

total brush height $=0.51, \ln ($ brush area $)=0.61$. Using PC1 scores as an index of overall brush size, a one-way ANOVA revealed that brush size depended on diet, because lowdiet males had smaller brushes than high-diet males (low diet: $N=16$, mean $\pm S E=-0.12 \pm 0.05$; high diet: $N=23$, mean $\left.\pm \mathrm{SE}=0.08 \pm 0.04 ; F_{1,37}=9.24, P=0.004\right)$. Using a regression of PC1 for body size against PC1 for brush size, we found a significant relationship between body size and brush size for both low- and high-diet males $\left(r^{2}=0.34\right.$, $P=0.0019$; Figure 3). However, given that diet influenced body size, these findings are not surprising. Thus, to control for body size when assessing brush size, we used the residuals from a brush size (PC1 brush size) by body size (PC1 body size) regression in a one-way ANOVA assessing the effect of diet. We found that when controlling for body size, brush size was not dependent on $\operatorname{diet}\left(F_{1,38}=1.8\right.$, $P=0.18)$.

\section{Diet and Mate Choice}

Copulation frequency did not depend on female diet treatment, as both low- and high-diet females were equally likely to mate $\left(x_{1}^{2}=0.23, P=0.63\right.$; Figure 4$)$. Of the females that mated, however, a female's choice of mates was dependent on female diet. High-diet females mated more with high-diet males, whereas low-diet females showed no mate selectivity $\left(X_{1}^{2}=5.89, P=0.015\right.$; Figure 4$)$. To de-

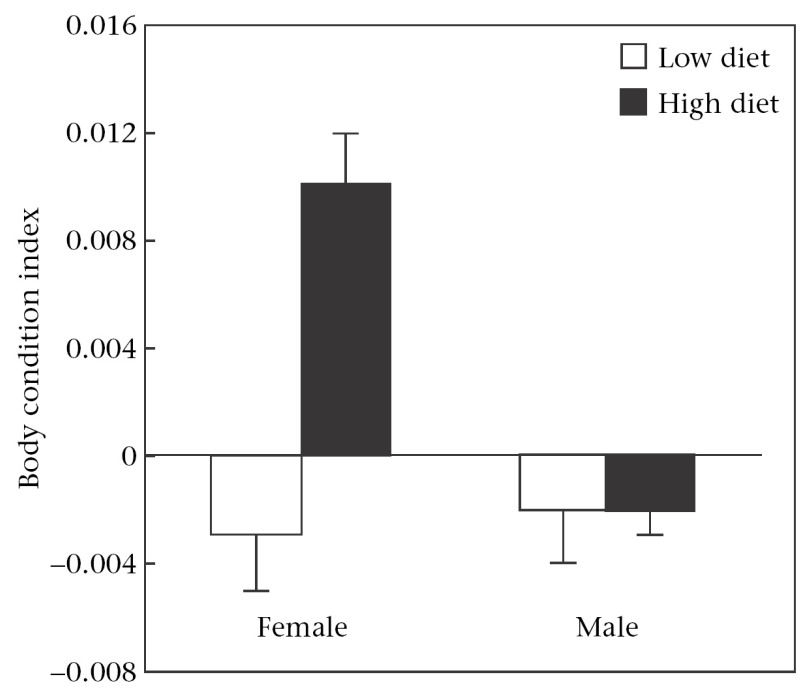

Figure 2. Body condition index (residuals of a regression of maturation weight and cephalothorax width) of male and female wolf spiders reared on low- versus high-diet treatments. termine whether male form (brush-legged versus non-ornamented) influenced mate selectivity, we did a combined analysis looking for an effect of female diet, male phenotype, and an interaction between the two on female mate choice. We found that only female diet influenced female choice of mates (high- versus low-diet male) and not male phenotype (nominal logistic model: female diet: $X_{1}^{2}=7.53, P=0.006$; male phenotype: $X_{1}^{2}=2.56, P=0.11$; diet $\times$ phenotype: $\left.X_{1}^{2}=1.36, P=0.24\right)$. In other words, high-diet females preferred high-diet males regardless of whether they were comparing brush-legged males or nonornamented males. When we excluded all trials in which a male was reused, we found the same significant pattern of mate choice: low-diet females $(N=5)$ copulated with high-diet males $60 \%$ of the time, whereas high-diet females $(N=7)$ copulated with high-diet males $100 \%$ of the time $\left(X_{1}^{2}=4.08, P=0.04\right)$. The time between first courtship and copulation depended on female diet treatment as well, but not on the copulating male's diet treatment. High-diet females mated more quickly than low-diet females, regardless of whether they mated with a high- or a low-diet male (female diet: $F_{1,26}=4.94, P=0.04$; copulating male's diet treatment: $F_{1,26}=3.19, P=0.09$; female diet $\times$ copulating male's diet: $F_{1,26}^{126}=0.05, P=0.8$; Figure 5).

Individual age was not normally distributed, and we were unable to transform the data; thus, we used nonparametric statistics. Since we needed to wait for low-diet

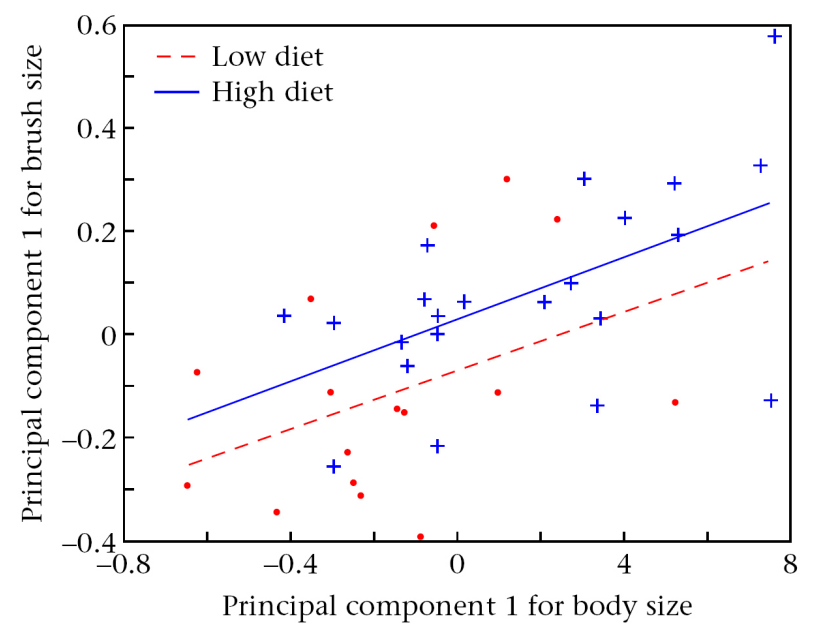

Figure 3. Regression of brush size and body size for brush-legged male wolf spiders reared on low- and high-diet treatments $\left(r^{2}=0.34\right.$, $P=0.0019)$. 


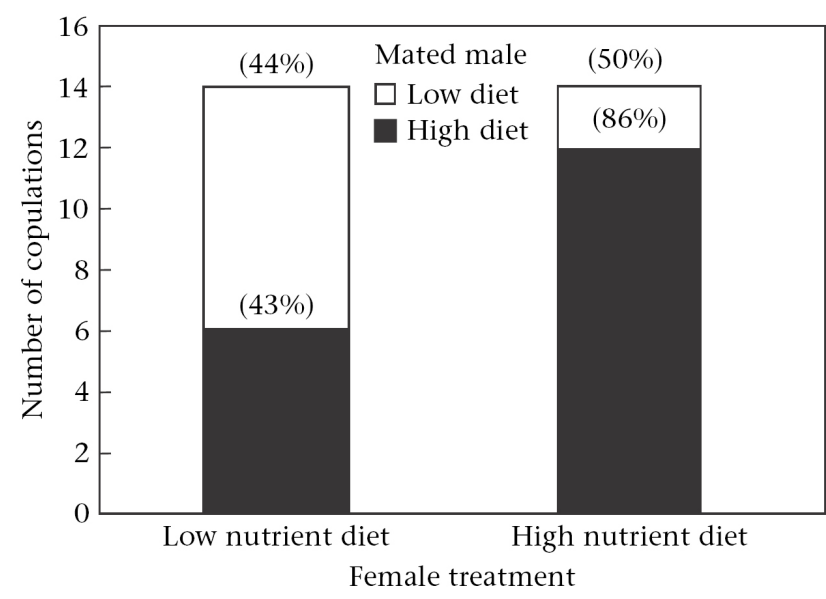

Figure 5. Time to copulation for female wolf spiders on low and high diets mating with low- and high-diet males. ${ }^{*} P<0.05$.

males to mature before running our simultaneous mate choice trials, female age at the time of mate choice trials differed significantly between high- and low-diet females: low-diet females were younger on average than high-diet females (low-diet: mean $\pm \mathrm{SE}=24.2 \pm 1.7$ days post maturation, $N=29$; high-diet: mean $\pm \mathrm{SE}=32.6 \pm 1.8$ days post maturation, $N=25$; Wilcoxon two-sample test: $Z=3.67$, $P=0.0002)$. If our mate choice data were to be explained by female age alone (i.e. older females prefer high-diet males, whereas younger females are not selective in their mate choice), then we would expect that females that mated with high-diet males would be older on average than those that mated with low-diet males. In contrast, we found no difference in age between females that mated with low- versus high-diet males (low-diet mate choice male: $N=10$, mean $\pm \mathrm{SE}=21.8 \pm 3.3$ days post maturation; high-diet mate choice male: $N=18$, mean $\pm \mathrm{SE}=30 \pm 2.5$ days post maturation, Wilcoxon two-sample test: $Z=-1.8, P=0.07)$. The power of our test (at $\alpha=0.05$ ) is estimated at $1-\beta=0.48$. There was no difference in age between high- and low-diet males used in mate choice trials (low-diet male: $N=38$, mean $\pm \mathrm{SE}=32.79 \pm 1.8$ days post maturation; high-diet male: $N=40$, mean $\pm S E=35.6 \pm 1.7$ days post maturation; Wilcoxon two-sample test: $Z=-1.3, P=0.21$ ).

High- and low-diet males did not appear to differ in their courtship and/or mating effort. For trials in which a copulation occurred, there was no difference between the high- and low-diet males with respect to which male courted first (low-diet copulating males, $N=10$ : simultaneous courtship $=60 \%$, high-diet male courted first $=20 \%$, low-diet male courted first $=20 \%$; high-diet copulating males, $N=18$ : simultaneous courtship $=39 \%$, high-diet male courted first $=22 \%$, low-diet male courted first $=39 \%$; $\left.X_{1}{ }^{2}=1.38, P=0.5\right)$. In addition, female mate choice did not depend on which male courted first $\left(\mathrm{X}_{1}{ }^{2}=1.38, P=0.5\right)$. For all trials, regardless of the male form or diet treatment, once a male began courting, he typically continued throughout the duration of the trial. In 20 of the 60 trials (33\%), at least one of the males unsuccessfully attempted to mount the female, suggesting that male mating effort does not neces-

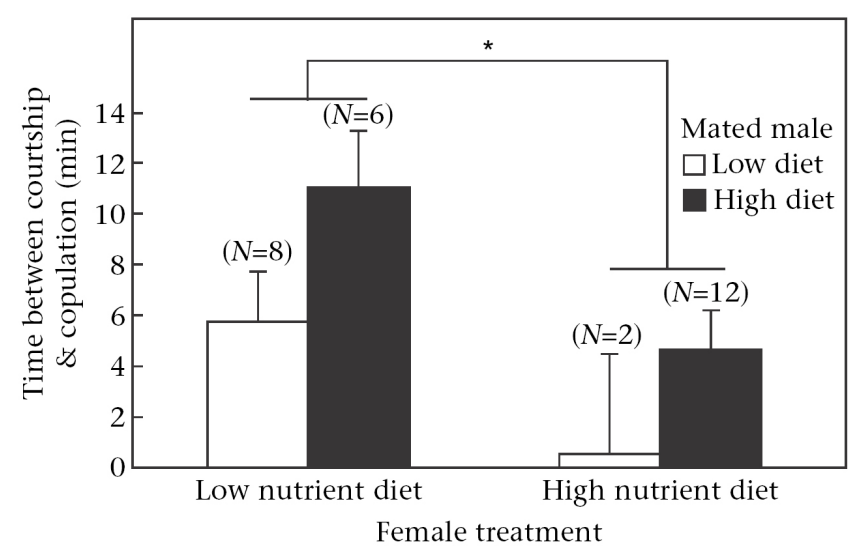

Figure 4. Female mate choice (number of copulations) for female wolf spiders on low and high diets.

sarily result in mating and, instead, that females probably control matings. Furthermore, there was no difference in the number of attempted mounts between low- and highdiet males (low-diet male: mean $\pm \mathrm{SE}=0.65 \pm 0.21$; highdiet male: mean $\pm \mathrm{SE}=0.55 \pm 0.18, P=0.28$ ) and there was a strong correlation between the number of attempted mounts between low- and high-diet males within trials, suggesting similar mating effort between males $\left(r^{2}=0.80\right.$, $\left.F_{1,58}=237.3, P<0.0001\right)$.

\section{Discussion}

Using laboratory-based diet manipulations, we found that late-juvenile diet history influenced development, adult size and adult female mate choice in a mixed population of Schizocosa wolf spiders. While previous studies have documented a life-long effect of diet on development, size at maturation and secondary sexual traits in the wolf spider S. ocreata (brush-legged males) (Uetz et al., 2002), this is the first study to document condition-dependent mate choice in a spider. Even though females reared on low- and high-nutrient diets were equally likely to mate, high-diet females mated significantly more with high-diet males than with low-diet males, whereas low-diet females showed no mate selectivity. The diet manipulations used were implemented only during the last few juvenile stages, in contrast to the results obtained from life-long feeding regimes used in earlier studies (Uetz et al., 2002) and the fact that we recorded such extreme differences in growth, development and behavior over such a relatively short period imply that these traits are extremely sensitive to environmental conditions such as food availability.

Although our results suggest increased mate choice selectivity in high-diet females, one could argue that our findings are the consequence of male mate choice as opposed to female mate choice: high-diet males may be more discriminating and may choose high-diet females more than they do low-diet females. If true, we might expect high-diet males to court high-diet females more vigorously, to initiate courtship more readily and to attempt mounts more 
frequently. Instead, we found no differences between highand low-diet males with respect to which male courted first, how long males courted, or how many mounts males attempted. In fact, we found a strong correlation between the number of mounts attempted by high- and low-diet males within a trial, suggesting equal mating effort. Furthermore, male mate choice has never been documented in any Schizocosa species, while multiple studies have documented examples of female choice (e.g. Hebets, 2003; Hebets, 2005; Hebets et al., 2006; Hebets and Vink, 2007; Uetz and Norton, 2007; reviewed in Uetz \& Roberts, 2002).

In addition to our finding of condition-dependent female mate choice, our results also suggest that the development of male form in this apparently polymorphic Schizocosa population is not diet dependent. We found no significant difference in the number of individuals that developed into brush-legged versus non-ornamented males between the diet treatments. If male form were condition dependent, we might expect more non-ornamented males to have developed under low-diet conditions and more brush-legged males to have developed under high-diet conditions. Although this pattern held, it was not significant. None the less, it is again important to note that these diet treatments were only conducted over the last few juvenile stages, leaving open the possibility that early nutritional variation can influence ultimate male form.

While prior theoretical work has predicted a positive correlation between female choosiness and body condition, much of the work is based on the assumption that choosiness is costly and that only high-quality females are capable of sustaining this cost (Janetos, 1980; Parker, 1983; Gibson and Bachman, 1992). In discussions of mate choice costs, it is often assumed that there are time and energy costs to choosiness. If such mate choice costs were to explain our results, we would expect low-quality females to make quicker mate choice decisions than high-quality females, since they would not be willing to suffer the cost of male assessment. In contrast, our results reveal that highdiet females make faster mate choice decisions than lowdiet females, a pattern opposite to that predicted based on time and energy costs. However, in our study, latency to copulate may have been confounded by differences in female age. For example, while adult mate choice may be influenced by female condition (e.g. previous diet treatment), latency to mate choice may be influenced by female age, with older females making faster decisions than younger females. Unfortunately, our female diet treatment was confounded by female age, and we are not able to tease apart these effects in the present study. However, results from a study on the same Schizocosa population (Hebets \& Vink, 2007) indicate that there is no correlation between female age and latency to copulation $\left(F_{1,44}=0.99, P=0.33\right)$, suggesting that female age cannot explain the observed copulation latency differences in our study.

Instead of differential costs explaining our results, highdiet females may simply be better able to discriminate among males. For example, a study using diet manipulations found that male drumming rate in the wolf spider Hygrolycosa rubrofasciata is condition dependent (Kotiaho,
2000). As such, it seems likely that our diet manipulations also affected various components of male courtship signaling. Given this, if the sensory or processing system of highdiet females allows for better discrimination among courtship signals, one might make two predictions: (1) high-diet females should choose high-diet males more reliably over low-diet males and (2) high-diet females should make their mate choice decisions more quickly. Both predictions are consistent with our results. An alternative, but not mutually exclusive, explanation is that the motivation to mate is lower for low-diet females. Since females tend to mate only once (Norton \& Uetz, 2005), and since a female's condition at the time of mating may significantly affect her ultimate fitness, a female may be less likely to engage in copulation when in poor condition. For example, females in poor condition may be more focused on foraging than on mating. This could result in both an increased latency to copulation and in a reduced selectivity of mates, again predictions that are concordant with our results. In essence, a female may devote her limited resources to food acquisition as opposed to mate acquisition. While this explanation remains a possibility, we might also expect a difference in overall likelihood to mate: higher mating frequency for high-diet females as compared to low-diet females. Instead, our results show that both high- and low-diet females are equally likely to mate. None the less, our mate choice trial duration may have been unnaturally long (45 $\mathrm{min}$ ), resulting in a higher proportion of low-diet female matings than might be expected under natural field conditions. Further experiments are clearly necessary to tease apart the alternative explanations for why high-diet, but not low-diet females are choosey in this system.

Unfortunately, because of the effect of diet treatment on maturation time (i.e. high-diet individuals matured earlier than low-diet individuals), we could not begin running high-diet females until we had sufficient numbers of mature low-diet males. As a result, our high-diet females were older on average than our low-diet females, potentially confounding the effects of diet treatment and age on female mate choice. For example, older females may show stronger selectivity in their mate choice than younger females, independent of their diet treatment. Although possible, we feel that this is highly unlikely for the following reasons. First, if this were the case, we might expect that females that mated with high-diet males would be older on average than those that mated with low-diet males. Although our results showed a pattern in this direction, we found no statistical difference in age between females that mated with high- versus low-diet males (see Results). More importantly, however, recent research on S. ocreata (a brushlegged species similar to the brush-legged males used in this study) showed that female choosiness decreases, not increases, with age (Uetz \& Norton, 2007). Using the videoplayback technique, Uetz \& Norton (2007) found that females show the strongest selectivity of male secondary sexual traits (brush-size in this case) between 15 and 21 days post maturation, with selectivity subsequently declining after 3 weeks postmaturity. In our study, low-diet females were on average 24 days old, whereas high-diet females 
were on average 32 days old. If age were to explain our results, we might expect the low-diet females to have shown stronger mate choice selectivity than high-diet females, the opposite pattern to that observed. Decreased choosiness with age seems to be common and has been demonstrated across numerous other taxa as well (e.g. guppies: KodricBrown \& Nicoletto, 2001; cockroaches: Moore \& Moore, 2001).

Since one goal of this study was to ensure differences between our diet groups, the treatments used in this experiment involved both quality and quantity manipulations, making it impossible to determine which variable was most important in explaining our results. In a previous study using S. ocreata, only diet quantity was manipulated, and while development time, adult size and secondary sexual traits were shown to depend on food quantity during development, that study did not address any aspects of individual behavior (Uetz et al., 2002). Several recent studies, however, suggest that the nutritional quality of food can influence a variety of behaviors in arthropods, including courtship (Wagner and Hoback, 1999; Holzer et al., 2003; Hunt et al., 2004; Bertram et al., 2006) and mating (Mallard \& Barnard, 2004). In addition, it has been suggested that predatory arthropods such as spiders are frequently nutrient limited in nature (Denno and Fagan, 2003; Fagan and Denno, 2004) and that food quantity is also often limited (Wise, 1993; Wise, 2006). These studies in combination with our results suggest that under natural conditions, food quantity and/or quality could significantly affect female mate choice and the evolution of male secondary sexual traits.

Given that predatory arthropods may be limited with respect to both prey quality (i.e. nutrients) and prey quantity, it is interesting to consider the implications of our results for natural populations. Unfortunately, we did not have condition measurements of mature virgin females from the field for comparison, but such comparisons could elucidate the extent to which condition-dependent mate choice may influence the evolution of male secondary sexual traits under natural conditions. For example, under the strict guidelines set forth for studies involving vertebrates, it follows that individuals maintained in laboratory situations are likely to be in much better condition on average than those found in the field. If true, and if condition-dependent mate choice is prevalent across vertebrate taxa, laboratory-based studies could easily provide an overestimate of the effect and potential strength of female choice under natural conditions, potentially limiting our current understanding of the importance of sexual selection in male trait evolution.

In summary, this study documents condition-dependent female mate choice in a population of Schizocosa wolf spiders. To determine the extent to which condition-dependent mate choice may influence the strength or direction of selection in natural populations, however, more data are necessary on the extent to which female condition varies naturally in the field. Unfortunately, because of the necessity to control and/or manipulate condition to understand its influence on behavior, most studies of condition-dependent mate choice have taken place under artificial labora- tory conditions. Until these results can be directly compared to field conditions, we should be cautious in our discussions relating to the effect of condition-dependent mate choice on the strength of sexual selection.

\section{Acknowledgments}

Ike Bromley measured the CW and CL of all of the individuals used in the size analyses. Courtney Rudd aided in spider maintenance and mate choice trials. Megumi Fuse and K. Fowler-Finn aided in spider maintenance. Stephanie Reed raised the spiders on their respective diet treatments as part of the Undergraduate Research Apprenticeship Program at the University of California, Berkeley. M. Adams, K. Fowler-Finn, T. Hinkelman, A. Rundus, R. Santer, S. Schwartz, J. Storz, D. Wilgers, and R. Willemart provided valuable comments on an earlier draft of this manuscript.

\section{References}

Andersson, M. 1994. Sexual Selection. Princeton, New Jersey: Princeton University Press.

Archard, G. A., Cuthill, I. C. \& Partridge, J. C. 2006. Conditiondependent mate choice in the guppy: a role for short-term food restriction? Behaviour, 143, 1317-1340.

Bertram, S. M., Schade, J. D. \& Elser, J. J. 2006. Signalling and phosphorus: correlations between mate signalling effort and body elemental composition in crickets. Animal Behaviour, 72, 899-907.

Borg, A. A., Forsgren, E. \& Amundsen, T. 2006. Seasonal change in female choice for male size in the two-spotted goby. Animal Behaviour, 72, 763-771.

Burley, N. T. \& Foster, V. S. 2006. Variation in female choice of mates: condition influences selectivity. Animal Behaviour, 72,713-719.

Coleman, S. W., Patricelli, G. L. \& Borgia, G. 2004. Variable female references drive complex male displays. Nature, 428 , 742-745.

Collins, S. A. 1995. The effect of recent experience on female choice in zebra finches. Animal Behaviour, 49, 479-486.

Cotton, S., Rogers, D. W., Small, J., Pomiankowski, A. \& Fowler, K. 2006. Variation in preference for a male ornament is positively associated with female eyespan in the stalk-eyed fly Diasemopsis meigenii. Proceedings of the Royal Society of London, Series B, 273, 1287-1292.

Denno, R. F. \& Fagan, W. F. 2003. Might nitrogen limitation promote omnivory among carnivorous arthropods? Ecology, 84, 2522-2531.

Fagan, W. F. \& Denno, R. F. 2004. Stoichiometry of actual vs. potential predatoreprey interactions: insights into nitrogen limitation for arthropod predators. Ecology Letters, 7, 876-883.

Gibson, R. M. \& Bachman, G. C. 1992. The costs of female choice in a lekking bird. Behavioral Ecology, 3, 300-309.

Hebets, E. A. 2003. Subadult experience influences adult mate choice in an arthropod: exposed female wolf spiders prefer males of a familiar phenotype. Proceedings of the National Academy of Sciences, U.S.A., 100, 13390-13395. 
Hebets, E. A. 2005. Attention-altering signal interactions in the multimodal courtship display of the wolf spider Schizocosa uetzi. Behavioral Ecology, 16,75-82.

Hebets, E. A. \& Vink, C. J. 2007. Experience leads to preference: experienced females prefer brush-legged males in a population of syntopic wolf spiders. Behavioral Ecology, 18, 1010-1020.

Hebets, E. A., Cuasay, K. \& Rivlin, P. K. 2006. The role of visual ornamentation in female choice of a multimodal male courtship display. Ethology, 112, 1062-1070.

Hedrick, A. V. \& Dill, L. M. 1993. Mate choice by female crickets is influenced by predation risk. Animal Behaviour, 46, 193-196.

Hingle, A., Fowler, K. \& Pomiankowski, A. 2001. The effect of transient food tress on female mate preference in the stalkeyed fly Cyrtodiopsis dalmanni. Proceedings of the Royal Society of London, Series B, 268, 1239-1244.

Holzer, B., Jacot, A. \& Brinkhof, M. W. G. 2003. Condition-dependent signaling affects male sexual attractiveness in field crickets, Gryllus campestris. Behavioral Ecology, 14, 353-359.

Hunt, J., Brooks, R., Jennions, M. D., Smith, M. J., Bentsen, C. L. \& Bussiere, L. F. 2004. High-quality male field crickets invest heavily in sexual display but die young. Nature, 432 , 1024-1027.

Hunt, J., Brooks, R. \& Jennions, M. D. 2005. Female mate choice as a condition-dependent life-history trait. American Naturalist, 166, 79-92.

Janetos, A. C. 1980. Strategies of female mate choice: a theoretical analysis. Behavioral Ecology and Sociobiology, 7, 107-112.

Jennions, M. D. \& Petrie, M. 1997. Variation in mate choice and mating preferences: a review of causes and consequences. Biological Reviews of the Cambridge Philosophical Society, 72, 283-327.

Kodric-Brown, A. \& Nicoletto, P. F. 1996. Consensus among females in their choice of males in the guppy Poecilia reticulata. Behavioral Ecology and Sociobiology, 39, 395-400.

Kodric-Brown, A. \& Nicoletto, P. F. 2001. Age and experience affect female choice in the guppy (Poecilia reticulata). American Naturalist, 157, 316-323.

Kotiaho, J. S. 2000. Testing the assumptions of conditional handicap theory: costs and condition dependence of a sexually selected trait. Behavioral Ecology and Sociobiology, 48, 188-194.

Little, A. C. \& Mannion, H. 2006. Viewing attractive or unattractive same-sex individuals changes self-rated attractiveness and face preferences in women. Animal Behaviour, 72, 981-987.

Little, A. C., Burt, D. M., Penton-Voak, I. S. \& Perrett, D. I. 2001. Self-perceived attractiveness influences human female preferences for sexual dimorphism and symmetry in males faces. Proceedings of the Royal Society of London, Series $B, 268,39-44$.

Lopez, S. 1999. Parasitized female guppies do not prefer showy males. Animal Behaviour, 57, 1129-1134.

Mallard, S. T. \& Barnard, C. J. 2004. Food stress, fluctuating asymmetry and reproductive performance in the gryllid crickets Gryllus bimaculatus and Gryllus sigillatus. Behaviour, 141, 219-232.
Moore, P. J. \& Moore, A. J. 2001. Reproductive aging and mating: the ticking of the biological clock in female cockroaches. Proceedings of the National Academy of Sciences, U.S.A., 98, 9171-9176.

Norton,S.\&Uetz,G.W.2005. Mating frequency in Schizocosa ocreata (Hentz) wolf spiders: evidence for a mating system with female monandry and male polygyny. Journal of Arachnology, 33,16-24.

Parker, G. A. 1983. Mate quality and mating decisions. In: Mate Choice (Ed. by P. Bateson), pp. 141-166. Cambridge: Cambridge University Press.

Pfennig, K. S. \& Tinsley, R. C. 2002. Different mate preferences by parasitized and unparasitized females potentially reduces sexual selection. Journal of Evolutionary Biology, 15, 399-406.

Poulin, R. 1994. Mate choice decisions by parasitized female upland bullies, Gobiomorphus breviceps. Proceedings of the Royal Society of London, Series B, 256, 183-187.

Rowe, L. \& Houle, D. 1996. The lek paradox and the capture of genetic variance by condition dependent traits. Proceedings of the Royal Society of London, Series B, 263, 1415-1421.

Stratton, G. E. 2005. Evolution of ornamentation and courtship behavior in Schizocosa: insights from a phylogeny based on morphology (Araneae, Lycosidae). Journal of Arachnology, 33, 347-376

Syriatowicz, A. \& Brooks, R. 2004. Sexual responsiveness is condition-dependent in female guppies, but preference functions are not. BMC Ecology, 4,5.

Toft, S. \& Wise, D. H. 1999. Growth, development, and survival of a generalist predator fed single-and mixed-species diets of different quality. Oecologia, 199, 191-197.

Uetz, G. W. \& Norton, S. 2007. Preference for male traits in female wolf spiders varies with the choice of available males, female age, and reproductive state. Behavioral Ecology and Sociobiology, 61,631-641.

Uetz, G. W. \& Roberts, J. A. 2002. Multisensory cues and multimodal communication in spiders: insights from video/ audio playback studies. Brain, Behavior and Evolution, 59, 222-230.

Uetz, G. W., Papke, R. \& Kilinc, B. 2002. Influence of feeding regime on body size, body condition and a male secondary sexual character in Schizocosa ocreata wolf spiders (Araneae, Lycosidae): condition-dependence in a visual signaling trait. Journal of Arachnology, 30, 461-469.

Wagner, W. E. \& Hoback, W. W. 1999. Nutritional effects on male calling behaviour in the variable field cricket. Animal Behaviour, 57, 89-95.

Widemo, F. \& Saether, S. A. 1999. Beauty is in the eye of the beholder: causes and consequences of variation in mating preferences. Trends in Ecology \& Evolution, 14, 26-31.

Wise, D. H. 1993. Spiders in Ecological Webs. Cambridge: Cambridge University Press.

Wise, D. H. 2006. Cannibalism, food limitation, intraspecific competition and the regulation of spider populations. Annual Review of Entomology, 51, 441-465. 